\title{
Calibrating Weather Forecasting in Indonesia: The Geostatistical Output Perturbation Method
}

\author{
Sutikno $^{1 \mathrm{a}}$, Purhadi ${ }^{1 \mathrm{~b}}$, Imam Mukhlash ${ }^{2 \mathrm{c}}$, Kartika Nur 'Anisa'1d*, Urip Haryoko ${ }^{3 \mathrm{e}}$, Hastuadi \\ Harsa $^{3 f}$ \\ ${ }^{1}$ Department of Statistics, Faculty of Mathematics Computing and Data Science, Institut Teknologi Sepuluh Nopember,

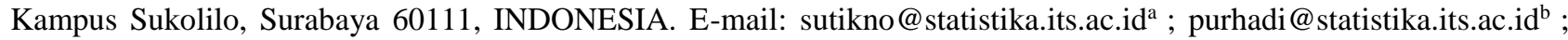 \\ kartika.nuranisa9@gmail.com ${ }^{\mathrm{d}}$ \\ ${ }^{2}$ Department of Mathematics, Faculty of Mathematics Computing and Data Science, Institut Teknologi Sepuluh \\ Nopember, Kampus Sukolilo, Surabaya 60111, INDONESIA. E-mail: imamm@ matematika.its.ac.id ${ }^{\mathrm{c}}$ \\ ${ }^{3}$ Centre for Research and Development Indonesian Agency for Meteorology, Climatology, and Geophysics, Jakarta \\ 10720, INDONESIA. E-mail: urip.haryoko@bmkg.go.id ; hastuadi@gmail.com ${ }^{\mathrm{f}}$ \\ * Corresponding Author: kartika.nuranisa9@gmail.com ${ }^{\mathrm{d}}$ \\ Received: $21^{\text {st }}$ April $2019 \quad$ Revised: 6 ${ }^{\text {th }}$ August 2019 \\ Published : $30^{\text {th }}$ September 2019
}

DOI : https://doi.org/10.22452/mjs.sp2019no2.9

\begin{abstract}
The Numerical Weather Prediction (NWP) was developed by the Meteorological, Climatological, and Geophysical Agency in Indonesia for the purpose of weather forecasting, however, it comes with a high level of bias. This purpose of this study therefore was to improve this model with the use of Geostatistical Output Perturbation (GOP), implemented in the conformal-cubic atmospheric model (CCAM) on NWP data from the eight meteorological stations in Indonesia, i.e. Kemayoran, Priok, Cengkareng, Pondok Betung, Curug, Dermaga, Tangerang and Citeko stations. The findings indicated exponential as the best distribution model for analyzing temperature in Indonesia using GOP. Also, locations which are considerably far away from other locations could have significant impact on the accuracy of the weather forecasts. In this case, Citeko station has quite different characteristics location considering the fact that it is located on higher elevation compared with other stations. Therefore, the exclusion of Citeko station produced better forecasting in terms of accuracy and precision, increasing to about twice the result when the station was included in the analysis.
\end{abstract}

Keywords: GOP, NWP, spatial, weather forecasting.

\section{INTRODUCTION}

Accurate information on weather forecasting is very vital considering the fact that weather conditions directly and indirectly impact on human's activities such as determining the harvesting period of crops (agriculture), time of fishing (fishery), and feasibility of flight or voyage (transportation). Also, accurate and up to date weather forecasting has the capacity to minimize the risk of disasters due to weather or hydrometeorology.

The weather condition of Indonesia is unique due to its location between the Pacific and Indian oceans, as well as the monsoon climates with dynamic weather and atmospheric conditions (Tjasyono \& Harijono, 2008). Therefore, the process of analyzing information about weather forecasting in the short, medium or long-term should be done continuously in order to find the most appropriate methods to capture the weather characteristics in each region.

A few years back, the Meteorological, Climatological and Geophysical Agency, Indonesia, (BMKG) developed the weather forecasting process using Numerical Weather 
Prediction (NWP) to support the method already in use. However, forecasting through NWP has a high level of bias because it is measured on a global scale (homogeneous) and unable to capture the dynamics fluctuations in the atmosphere (BMKG, 2011; Wilks, 2006). Therefore, to improve its accuracy, the output of NWP must be with the statistical post-processing.

Also, a study conducted by Safitri \& Sutikno (2012) showed that forecasting using NWP directly could result to bias outcomes. The authors went ahead and also used the Model Output Statistics (MOS) method and concluded that it improved the NWP model by $86 \%$, this model was observed in four stations. Another study by Narendra, Sutikno, \& Purhadi (2017) used Ensemble Model Output Statistics (EMOS) as the postprocessing technique to solve the bias forecasting and under-dispersion problems in Cengkareng station. However, previous studies did not consider the spatial correlation patterns which might impact on the forecasting results. Therefore, this study considered that aspect and observed that the stations have dependent relation with one another.

The Geostatistical Output Perturbation (GOP) is a method which reconstructs error from the outcome of the deterministic forecast, and not the input, to produce ensemble forecasts of any size (Gel, Raftery, \& Gneiting, 2004). Estimating the parameters for GOP is a common geostatistics modeling, which involves using maximum likelihood estimation (MLE) to estimate regression parameter with empirical semivariogram for the purpose of identifying the spatial correlation. According to Cressie (1985), the GOP spatial parameters are estimated by weighted least square from the semivariogram. Then, the forecasting from linear regression is added by an error which is simulated based on the spatial estimator in order to give the calibrated forecasting (Berrocal, Raftery, \& Gneiting, 2007). Also,
Feldmann (2012) found that GOP has the capacity to calibrate better temperature forecasts compared with the non-spatial methods, although GOP only uses the modification and simulation of one deterministic forecast. Therefore, the countries which do not have sufficient funds to develop enough NWPs, for example Indonesia, are only able to produce weather forecasts based on the ensemble.

Therefore, this study uses the GOP as the implemented method on weather data. In analyzing weather forecasting, the GOP considers the spatial correlation of all the locations or stations simultaneously. Although GOP only is based on one deterministic forecasting model, which has the spatial parameter for improving the forecasting result that could not identify the spatial cases. In this study, temperature was used as the response variable because it is the element of weather that has enough relation to rain event, air pressure, as well as humidity.

The section 2 of this study describes the Geostatistical Output Perturbation (GOP) method, spatial dependencies, variables used in the study, and the model evaluation, including the Root Mean Square Error (RMSE), Continuous Rank Probability Score (CRPS) and Coverage. The method was applied in section 3 to forecast temperature and show the results of the analysis. Finally, section 4 presents the conclusion and outlines some plans for future studies.

\section{METHOD AND MATERIALS}

\subsection{Geostatistical Output Perturbation}

Statistically, $S$ is a considerable set of observational and relatively large locations, where $t=1,2, \ldots, T$ and considering the multivariate aspect between the locations, comes $\mathbf{y}_{t}=\left[y_{1 t}, y_{2 t}, \ldots, y_{s t}\right]^{\prime}$ which is the weather element vector observed in all observational 
locations with size $s \times 1$ and $\mathbf{x}_{t}=\left[x_{1 t}, x_{2 t}, \ldots, x_{s t}\right]^{\prime}$ which is the weather forecast vector. Therefore, the GOP model is given as (1),

$$
\mathbf{y}_{t}=\beta_{0} \mathbf{1}+\beta_{1} \mathbf{x}_{t}+\boldsymbol{\varepsilon}_{t}
$$

where 1 is $s \times 1$ vector of which all elements are 1 and $\varepsilon_{t}=\left[\varepsilon_{1 t}, \varepsilon_{2 t}, \ldots, \varepsilon_{s t}\right]^{\prime}$. The GOP model error of (1) follows the normal distribution with mean 0 and covariance $\Sigma$ which depends on the spatial covariance structure (Gel,

$$
\frac{1}{2} \operatorname{var}\left(\varepsilon\left(\mathrm{s}_{i}\right)-\varepsilon\left(\mathrm{s}_{j}\right)\right)=\rho^{2}+\sigma^{2}\left(1-C\left(\mathrm{~s}_{i}, \mathrm{~s}_{j}\right)\right)
$$

with $\rho^{2}$ is nugget effect, i.e. the measurement of error variance and the size of the spatial diversity in the certain distance that still exerts an influence $\rho^{2}+\sigma^{2}$.is sill, i.e. total observed variation of the variable and the range, $r$ is the distance between two observations that could be considered
Raftery, \& Gneiting, 2004). If $C\left(\mathrm{~s}_{i}, \mathrm{~s}_{j}\right)$ in (2) are the stationary and isotropy functions, then the element value of $(i, j) \Sigma$ is obtained from

$$
\gamma(\mathbf{d})=\rho^{2}+\sigma^{2}(1-\exp (-\mathbf{d} / r))
$$

where d is $\left\|\mathrm{s}_{i}-\mathrm{s}_{j}\right\|$ that represents the Euclidean distance between the set of pairs of locations $s_{i}$ and $s_{j}$ and $r$ is the range (in $\mathrm{km}$ ) indicating the range of distances where the

$$
\begin{aligned}
& \gamma(\mathbf{d})=\rho^{2}+\sigma^{2}\left(1-\exp \left(-\mathbf{d}^{2} / r^{2}\right)\right) \\
& \gamma(\mathbf{d})=\rho^{2}+\sigma^{2}\left(\frac{3}{2} \cdot \frac{\mathbf{d}}{r}-\frac{1}{2} \cdot \frac{\mathbf{d}^{3}}{r^{3}}\right)
\end{aligned}
$$

\subsection{Spatial Dependencies}

One of the indicators normally used to identify spatial dependencies in data is the Moran's I which is based on a distance matrix W. This approach uses certain distance (in $\mathrm{km}$, meter, mile, etc) which is estimated to have the spatial influence between two locations. According to Anselin (1998), the element matrix $\mathbf{W}$ is given 1 when the distance is under cut-off part, otherwise, it is given 0 . Also, the proximity location is indicated as being linked when the value is positive and otherwise when it is negative. The equation (6) below represents the Moran's I based on a distance matrix $\mathbf{W}_{s \times s}$ standardized, while $\mathbf{x}$ is the observed vector $s \times 1$. 


$$
I=\frac{(\mathbf{x}-\overline{\mathbf{x}})^{\prime} \mathbf{W}(\mathbf{x}-\overline{\mathbf{x}})}{(\mathbf{x}-\overline{\mathbf{x}})^{\prime}(\mathbf{x}-\overline{\mathbf{x}})}
$$

The significance of Moran's I is tested through the normal approach (Cliff \& Ord, 1981). Also, in the case of spatial autocorrelation, the null hypothesis $\left(\mathrm{H}_{0}\right)$

always states that there is no spatial clustering of the values associated with the geographic features in the study area. The hypothesis testing is shown in equation

with $\quad \mathrm{E}(I)=-\frac{1}{n-1} ; \operatorname{var}(I)=\frac{n^{2} S_{1}-n S_{2}+3 S_{0}^{2}}{\left(n^{2}-1\right) S_{0}^{2}}-(\mathrm{E}(I))^{2} \quad$ and $\quad \operatorname{var}(I), \quad S_{0}=\sum_{i=1}^{n} \sum_{j=1}^{n} w_{i j}$; $S_{1}=\frac{1}{2} \sum_{i=1}^{n} \sum_{j=1}^{n}\left(w_{i j}+w_{j i}\right)^{2} ; S_{2}=\sum_{i=1}^{n}\left(\sum_{j=1}^{n} w_{i j}+\sum_{j=1}^{n} w_{j i}\right)^{2} . \mathrm{H}_{0}$ is rejected if $|Z(I)|>z_{1-\alpha / 2}$ where $z_{1-\alpha / 2}$ is quantile of $(1-\alpha / 2) \times 100 \%$ a normal standard distribution.

\subsection{Evaluating Calibrated Model}

The goodness of fit models does not give accurate measurements when only the root mean square error (RMSE) is used to calibrate the weather forecasts. According to Feldmann (2012), other methods are also needed to check the level of bias correction and sharpness of forecasts ensembles, such as the continuous rank probability score (CRPS) and coverage.

\section{Root Mean Square Error (RMSE)}

The RMSE is an indicator of accuracy obtained from the (8) square root of MSE, which is the sum of the squares of the difference between the forecast and observed values.

$$
\mathrm{RMSE}=\sqrt{\mathrm{MSE}}=\sqrt{\frac{1}{n} \sum_{i=1}^{n}\left(y_{i}-\hat{y}_{i}\right)^{2}}
$$

\section{Continuous Rank Probability Score} (CRPS)

The CRPS is used (9) to check how precise the predictive intervals are produced by calibration methods. According to Feldmann (2012), the lower the value, the more reliable the predictive interval.

$$
\mathrm{CRPS}=\frac{1}{n} \sum_{i=1}^{n} \operatorname{crps}\left(F_{i}, y_{i}\right)=\frac{1}{n} \sum_{i=1}^{n} \int_{-\infty}^{\infty}\left[F_{i}^{\text {forecast }}(y)-F_{i}^{\text {obs }}(y)\right]^{2} d y
$$

where $n$ is the number of observations, $i$ is time period (e.g. daily), $F_{i}^{\text {forecast }}(y)$ is predictive 
$\mathrm{CDF}$ at time $i$, and $F_{i}^{\text {obs }}(y)$ is empirical CDF at time $i$ (Anggraeni, 2013). If the threshold forecast < observation, then $F_{i}^{o b s}(y)=0$, however, it is 1 when the threshold forecast $\geq$ observation.

\section{Coverage}

The sharpness of the ensemble forecasts can be identified through coverage as shown in equation (10). According to Moller (2014), observations are said to be in the coverage when within an ensemble range.

$$
\frac{M-1}{M+1} \times 100 \%
$$

$M$ denotes the ensemble member and the ensemble forecast is calibrated if the empirical coverage is much closer to the standard coverage.

\subsection{Data and Variables}

Secondary data are used in this study, obtained from Meteorology, Climatology and Geophysics Agency (BMKG). Data of conformal-cubic atmospheric model (CCAM) NWP collected from 1st January 2009 to 31st December 2010 (708 days). The locations of the research are the meteorological stations in Kemayoran, Priok, Cengkareng, Pondok Betung, Curug, Dermaga, Tangerang and Citeko (Luthfi, Sutikno, \& Purhadi, 2018) as shown in Figure 1. The response variable in this study is observed air temperature, i.e. maximum and minimum temperature (Celsius). 


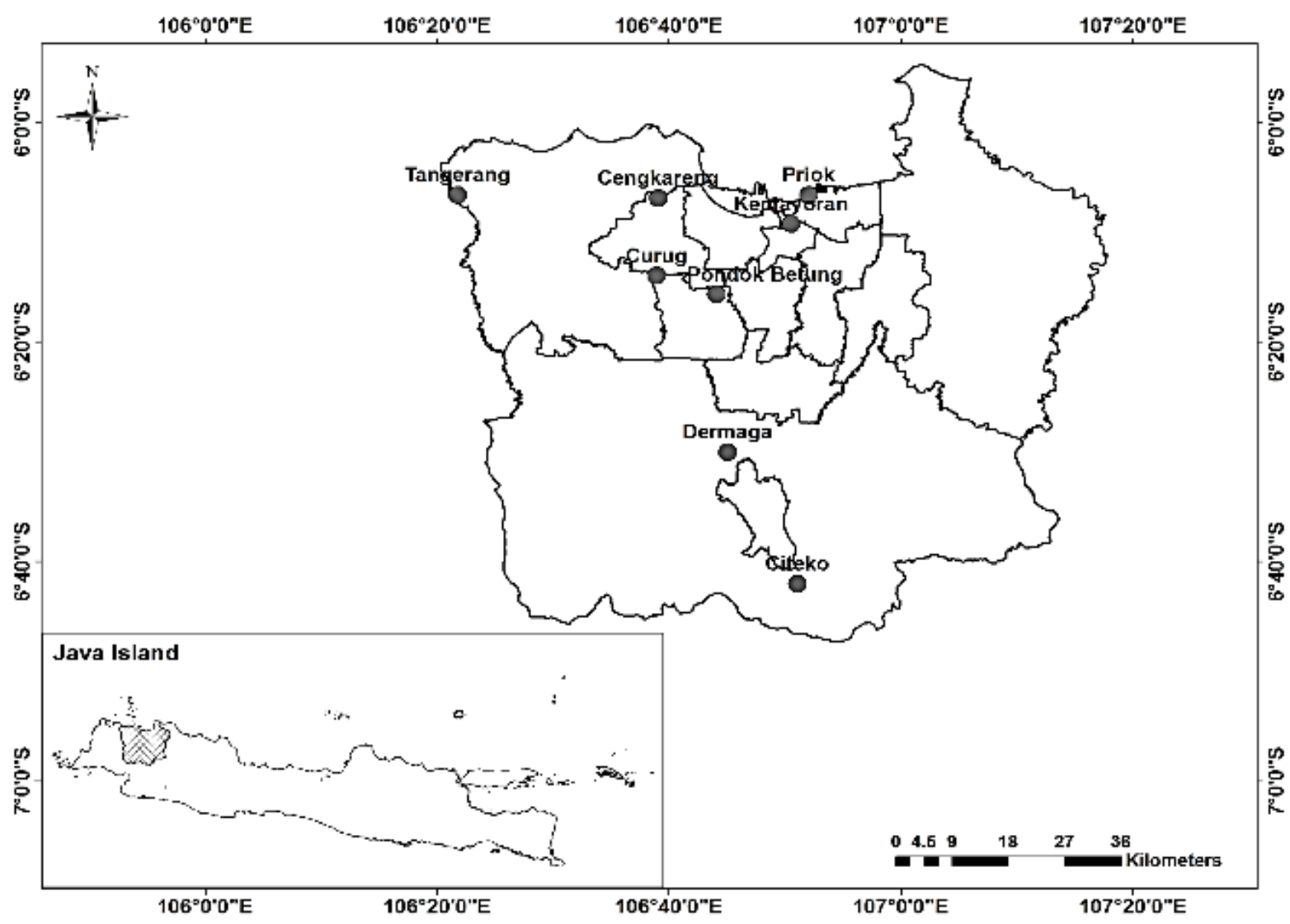

Figure 1: Meteorological stations for study region.

\section{RESULTS AND DISCUSSION}

\subsection{Spatial Dependencies}

The Moran's I is used to test the significance of spatial dependencies of the maximum temperature between the eight meteorology stations. Table 1 shows that Citeko has the farthest distance from the other stations. Based on BMKG (2011) and the assumption of uniform elevation (height) of the station, the cut-off distance is set at $30 \mathrm{~km}$. The standardized weighted distance matrix was used in order to get the Morgan's I. This is to make its range to be between -1 and 1 . The Moran's I of T $\mathrm{MAX}$ is 0.135 (p-value = 0.048 ) and $\mathrm{T}_{\mathrm{MIN}}$ is 0.379 ( $\mathrm{p}$-value $=0.006$ ). It means the spatial dependencies for $\mathrm{T}_{\mathrm{MAX}}$ and $\mathrm{T}_{\mathrm{MIN}}$ are statistically significant at $\alpha=5 \%$. It also means that the spatial strength of minimum temperature is higher than the maximum temperature (i.e. the Moran's I of $\mathrm{T}_{\mathrm{MIN}}$ is higher than $\mathrm{T}_{\mathrm{MAX}}$ ). More so, the closer stations have stronger relationships than those further apart.

Figure 2 shows that the temperature in most stations is related to each other. Despite the fact that Citeko and Dermaga stations are on the same quadrant, there is a weak correlation between them because of the geographical distant position. 
Table 1: Matrix of distance 8 meteorology stations $(\mathrm{km})$.

\begin{tabular}{c|cccccccc}
\hline Station & 1 & 2 & 3 & 4 & 5 & 6 & 7 & 8 \\
\hline 1 & 0 & 6,810 & 21,694 & 15,479 & 22,929 & 53,593 & 60,575 & 39,634 \\
2 & 6,810 & 0 & 24,091 & 22,091 & 28,231 & 56,130 & 66,818 & 46,372 \\
3 & 21,694 & 24,091 & 0 & 19,615 & 12,98 & 32,108 & 68,598 & 44,080 \\
4 & 15,479 & 22,091 & 19,615 & 0 & 11,609 & 46,443 & 50,027 & 26,550 \\
5 & 22,929 & 28,231 & 12,980 & 11,609 & 0 & 34,907 & 56,467 & 31,683 \\
6 & 53,593 & 56,130 & 32,108 & 46,443 & 34,907 & 0 & 85,158 & 61,212 \\
7 & 60,575 & 66,818 & 68,598 & 50,027 & 56,467 & 85,158 & 0 & 24,859 \\
8 & 39,634 & 46,371 & 44,080 & 26,550 & 31,683 & 61,212 & 24,859 & 0 \\
\hline
\end{tabular}

Note.:
$1:$ Kemayoran
$2:$ Priok
3 : Cengkareng
4 : Pondok Betung
5 : Curug
6: Tangerang $7:$ Citeko
8 : Dermaga

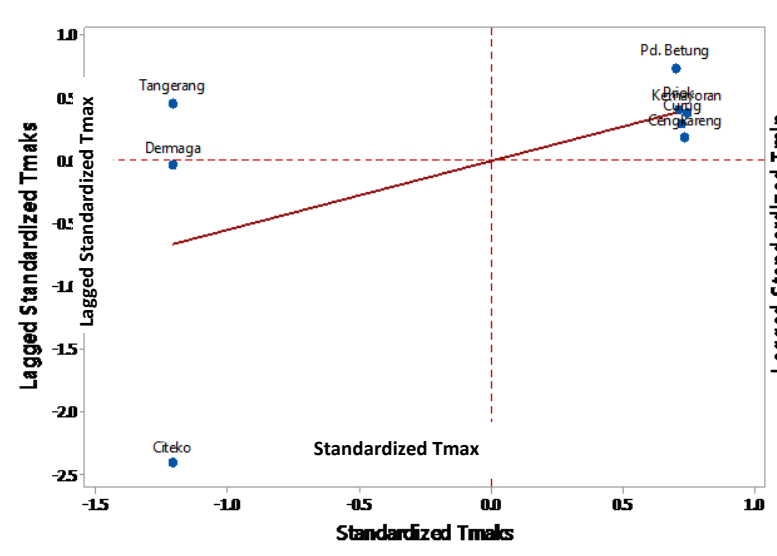

(a)

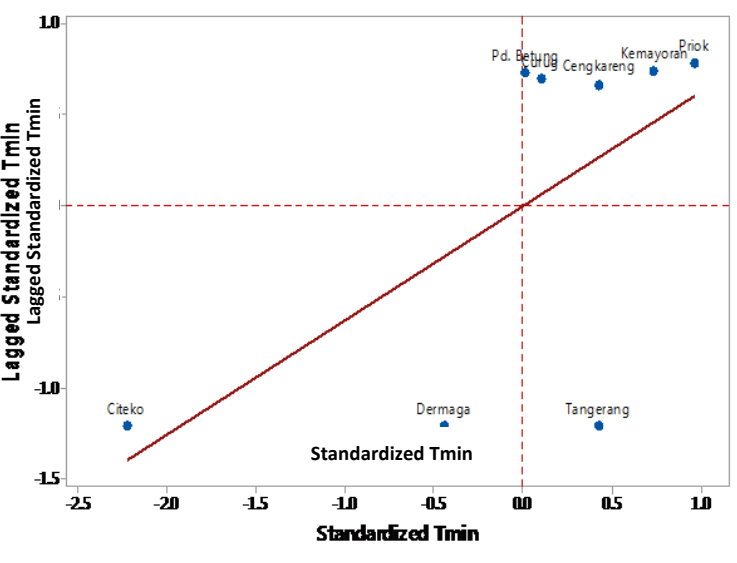

(b)

Figure 2: Moran's I plot of spatial correlation among stations: (a) maximum temperature and (b) minimum temperature.

\subsection{The Assessment of the Best Model}

Efforts were made to find the best semivariogram model for applying the temperature in Indonesia using three different models, i.e. exponential, Gaussian and spherical. The models are compared based on empirical semivariogram as shown in Figure 3 , then the model evaluation in Table 2, while the predictive checking by Verification Rank Histogram is presented in Figure 4.

Also, Figure 2 shows that spatial inconsistency exists on both the maximum and minimum temperature. On some distance pairs, there are few bins which have semivariance far greater than others. Since the patterns are seen in bins representing distance $50 \mathrm{~km}$ or more, it could be because Citeko, Tangerang and Dermaga stations are geographically located far from others, as seen in Figure 2. This has been the biggest effect on the unexpected inconsistency.

Figure 3 shows the construction of the residual of the GOP model to obtain the exponential, Gaussian and spherical semivariogram. The semivariogram is roughly constant on reaching a distance of about $8.69 \mathrm{~km}$. This implies that the temperature between two locations has no dependency after $8.69 \mathrm{~km}$, with sill recording 3.65 for 
maximum temperature and 2.53 for minimum temperature. The high amount of sill might result to a greater variance of estimation or influence the forecast. And despite the fact that the spherical semivariogram has the same range and sill values with other models for maximum and minimum temperature, it does not give the best semivariogram as shown in Figure 4c. (a)

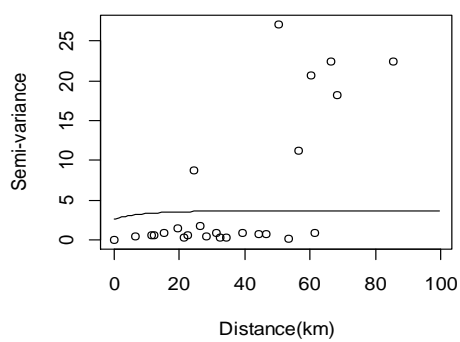

Exponential Model

(b)

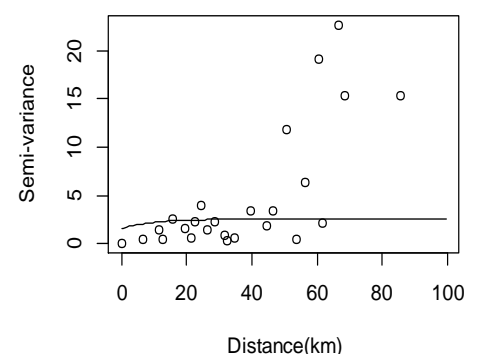

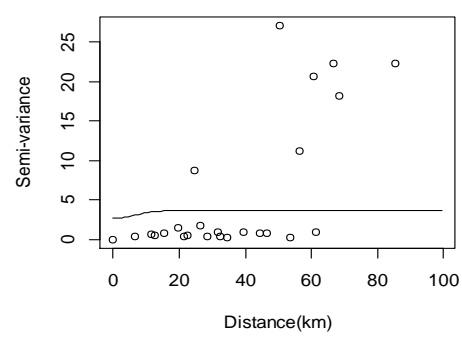

Gaussian Model

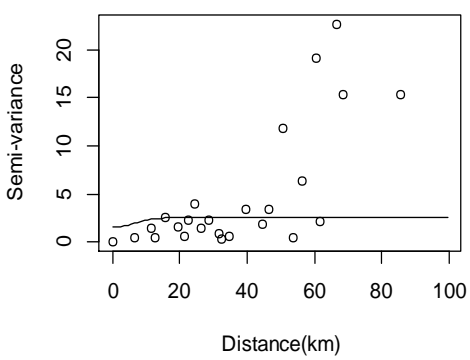

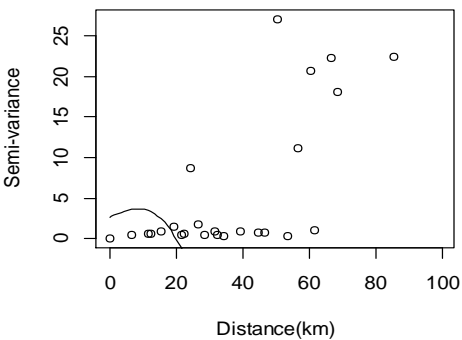

Spherical Model

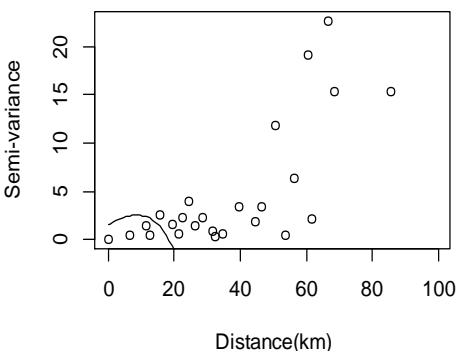

Figure 3: Empirical semivariogram over 30-day training period of temperature: (a) maximum temperature (b) minimum temperature.

Upon evaluation and comparing the GOP for the three models, the best model discovered was the exponential model as presented in Table 2.

Table 2: Comparison of evaluating GOP model, 31/1/2009 - 31/1/2010.

\begin{tabular}{lccccccccc}
\hline & \multicolumn{3}{c}{ Exponential } & \multicolumn{3}{c}{ Gaussian } & \multicolumn{2}{c}{ Spherical } \\
\cline { 2 - 10 } & $\begin{array}{c}\text { RMSE } \\
\left({ }^{\circ} \mathbf{C}\right)\end{array}$ & CRPS & $\begin{array}{c}\text { Coverage } \\
(\boldsymbol{\%})\end{array}$ & $\begin{array}{c}\text { RMSE } \\
\left({ }^{\circ} \mathbf{C}\right)\end{array}$ & CRPS & $\begin{array}{c}\text { Coverage } \\
(\boldsymbol{\%})\end{array}$ & $\begin{array}{c}\text { RMSE } \\
\left({ }^{\circ} \mathbf{C}\right)\end{array}$ & CRPS & $\begin{array}{c}\text { Coverage } \\
(\boldsymbol{\%})\end{array}$ \\
T $_{\text {MAX }}$ & 3.044 & 1.540 & 75.526 & 3.066 & 1.544 & 75.589 & 3.056 & 1.540 & 75.461 \\
$\mathbf{T}_{\text {MIN }}$ & 2.665 & 1.423 & 68.732 & 2.673 & 1.429 & 68.510 & 2.677 & 1.426 & 68.676 \\
\hline
\end{tabular}

As the other comparison, the predictive checking for GOP ensemble was applied for the predictions in all stations that used the three models from 1st January 2009 to 31 st December 2010. The verification rank histograms shown in Figure 4 give relatively same results and the abscissa shows the number of GOP ensemble and probable ordinate.

Considering the three criteria as shown in figures 3 and 4, as well as in Table 2, the exponential distribution is the best model for applying the temperature in Indonesia. 
(a)
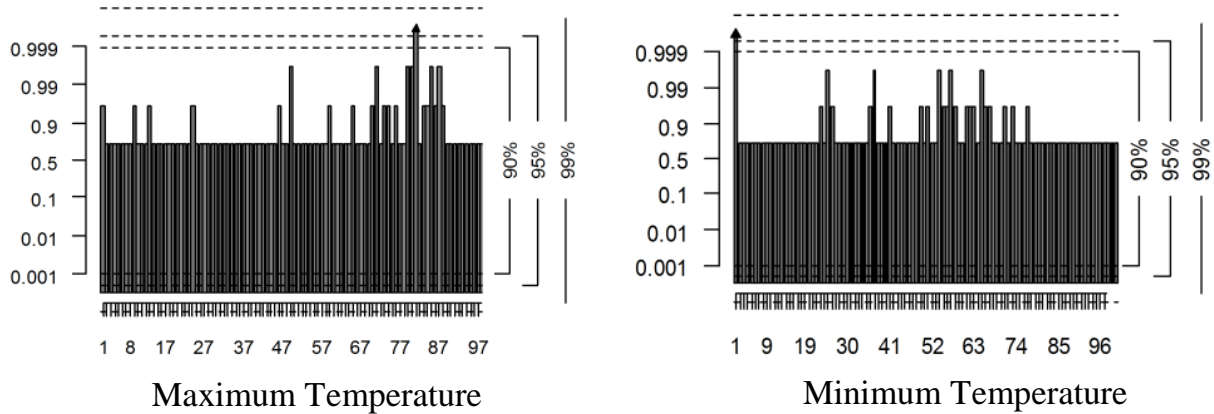

(b)
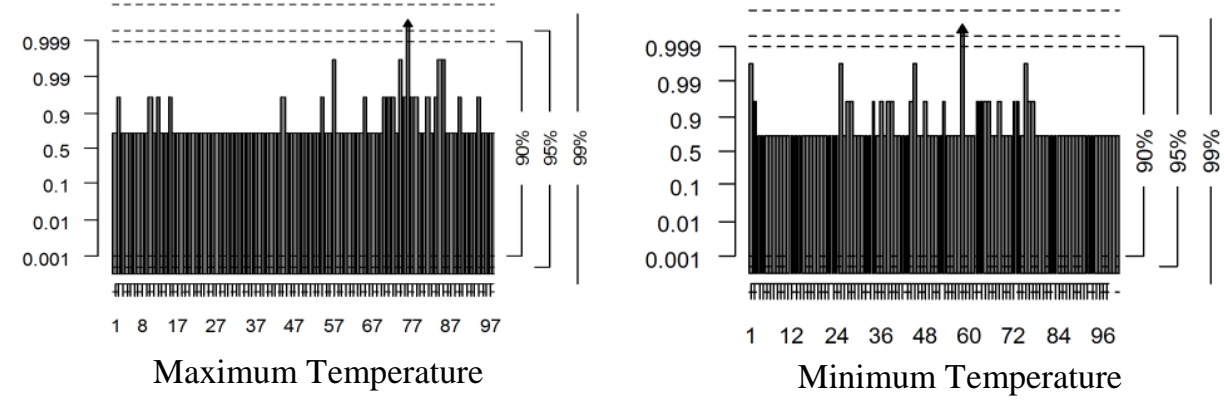

(c)
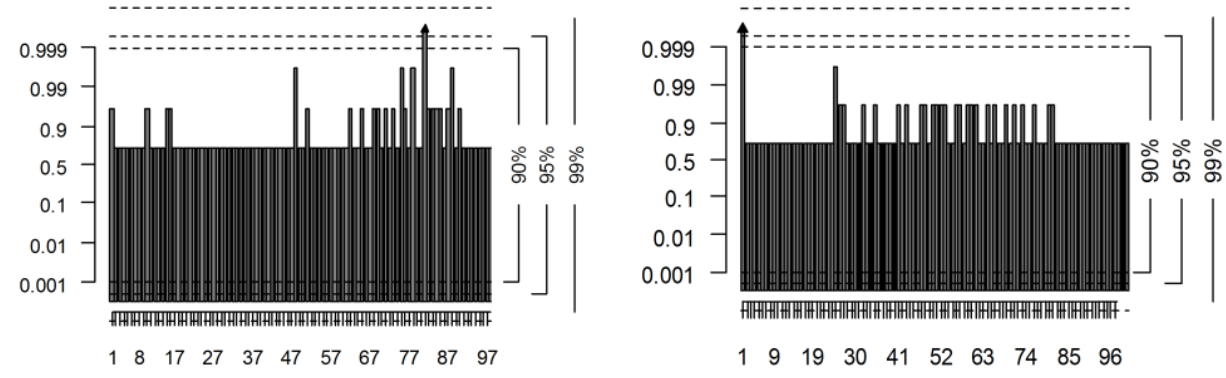

Maximum Temperature

Minimum Temperature

Figure 4: Verification rank histogram for GOP ensemble predictions, 31/1/2009 - 31/1/2010 (a) exponential, (b) gaussian, (c) spherical.

\subsection{Model Temperature Forecast}

The GOP models for both the maximum and minimum temperature with 30-day training period are presented as follow (11)

$$
\begin{aligned}
& \mathrm{T}_{\text {MAX } s, t}=1.785+0.959 \text { tmaxscr }_{s, t} \\
& \mathrm{~T}_{\text {MIN } s, t}=25.963-0.131 \text { tminscr }_{s, t}
\end{aligned}
$$

The GOP improves the bias correction rate as shown in Table 3, which reflected on the RMSE of GOP for maximum temperature $\left(2.13^{\circ}\right)$ which is lower (i.e. the model is better) than of NWP $\left(2.18^{\circ}\right)$, despite the fact that the RMSE of minimum temperature 
forecasting by GOP is not better than that of NWP. A strong reason for this weakness with regards to the accuracy of GOP is its failure to forecast temperatures in Citeko and Dermaga stations, which are geographically far from the other stations. This problem is compounded by the observed value in minimum temperature which does not fit into the $90 \%$ predictive interval for Citeko station. The GOP is strongly vulnerable and risky in case of inadequate location of interest, inappropriate data properties, data mishandle, etc.

Then, a remodeling process was conducted without Citeko station in order to get better results. Based on this, the new GOP models for temperature with 30-day training period are given as (12)

$$
\begin{aligned}
& \mathrm{T}_{\text {MAX } s, t}=4.739+0.885 \operatorname{tmaxscr}_{s, t} \\
& \mathrm{~T}_{\text {MIN } s, t}=21.894+0.074 \operatorname{tminscr}_{s, t}
\end{aligned}
$$

\begin{tabular}{|c|c|c|c|c|c|c|c|c|}
\hline $\begin{array}{c}\text { Temperat } \\
\text { ure }\end{array}$ & Station & $\begin{array}{l}\text { Obs. } \\
\left({ }^{\circ} \mathrm{C}\right)\end{array}$ & $\begin{array}{c}\text { NWP } \\
\left({ }^{\circ} \mathrm{C}\right)\end{array}$ & $\begin{array}{l}\text { GOP } \\
\left({ }^{\circ} \mathrm{C}\right)\end{array}$ & $\begin{array}{c}\mathbf{P}_{5} \\
\left({ }^{\circ} \mathbf{C}\right)\end{array}$ & $\begin{array}{c}\mathbf{P}_{95} \\
\left({ }^{\circ} \mathrm{C}\right)\end{array}$ & $\begin{array}{c}\text { RMSE of } \\
\text { NWP }\end{array}$ & $\begin{array}{c}\text { RMSE of } \\
\text { GOP }\end{array}$ \\
\hline \multirow{8}{*}{$\mathbf{T}_{\text {MAX }}$} & $\begin{array}{c}\text { Kemayor } \\
\text { an }\end{array}$ & 28.8 & 26.43 & 29.63 & 23.95 & 30.96 & \multirow{8}{*}{$2.18^{\circ}$} & \multirow{8}{*}{$2.13^{\circ}$} \\
\hline & Priok & 28.7 & 26.55 & 31.03 & 24.34 & 29.77 & & \\
\hline & $\begin{array}{l}\text { Cengkar } \\
\text { eng }\end{array}$ & 28.6 & 26.42 & 28.44 & 24.4 & 29.87 & & \\
\hline & $\begin{array}{c}\text { Pd. } \\
\text { Betung }\end{array}$ & 29.0 & 26.49 & 25.09 & 24.15 & 30.3 & & \\
\hline & Curug & 28.3 & 26.26 & 28.39 & 23.79 & 30.32 & & \\
\hline & $\begin{array}{c}\text { Tangeran } \\
\mathrm{g}\end{array}$ & 29.2 & 26.34 & 27.88 & 23.08 & 29.56 & & \\
\hline & Citeko & 25.0 & 26.77 & 26.76 & 23.95 & 30.58 & & \\
\hline & Dermaga & 27.8 & 26.73 & 24.66 & 24.33 & 30.32 & & \\
\hline $\begin{array}{c}\text { Temperat } \\
\text { ure }\end{array}$ & Station & $\begin{array}{l}\text { Obs. } \\
\left({ }^{\circ} \mathrm{C}\right)\end{array}$ & $\begin{array}{c}\text { NWP } \\
\left({ }^{\circ} \mathrm{C}\right)\end{array}$ & $\begin{array}{l}\text { GOP } \\
\left({ }^{\circ} \mathbf{C}\right)\end{array}$ & $\begin{array}{c}\mathbf{P}_{5} \\
\left({ }^{\circ} \mathbf{C}\right)\end{array}$ & $\begin{array}{l}\mathbf{P}_{95} \\
\left({ }^{\circ} \mathbf{C}\right)\end{array}$ & $\begin{array}{c}\text { RMSE of } \\
\text { NWP }\end{array}$ & $\begin{array}{l}\text { RMSE of } \\
\text { GOP }\end{array}$ \\
\hline \multirow{8}{*}{$\mathbf{T}_{\text {MIN }}$} & $\begin{array}{c}\text { Kemayor } \\
\text { an }\end{array}$ & 23.8 & 22.6 & 25.86 & 20.84 & 25.75 & \multirow{8}{*}{$1.57^{\circ}$} & \multirow{8}{*}{$2.27^{\circ}$} \\
\hline & Priok & 23.8 & 23.18 & 24.05 & 20.99 & 26.05 & & \\
\hline & $\begin{array}{l}\text { Cengkar } \\
\text { eng }\end{array}$ & 23.4 & 22.55 & 22.46 & 20.75 & 25.46 & & \\
\hline & $\begin{array}{l}\text { Pd. } \\
\text { Betung }\end{array}$ & 23.4 & 22.38 & 24.12 & 20.16 & 25.53 & & \\
\hline & Curug & 23.5 & 22.19 & 23.02 & 20.49 & 25.69 & & \\
\hline & $\begin{array}{c}\text { Tangeran } \\
\mathrm{g}\end{array}$ & 23.3 & 22.39 & 23.89 & 19.73 & 25.39 & & \\
\hline & Citeko & 18.4 & 22.08 & 23.72 & 20.92 & 25.38 & & \\
\hline & Dermaga & 22.4 & 22.24 & 24.97 & 20.67 & 25.46 & & \\
\hline
\end{tabular}

Table 3: RMSE of GOP forecast and NWP on January $31^{\text {st }}, 2009$. 
The regression parameters $\beta_{0}$ and $\beta_{1}$ for the maximum temperature (12) without Citeko station, are both significant at $\alpha=5 \%$, however on involving the (11) Citeko station, only $\beta_{1}$ for maximum temperature and $\beta_{0}$ for minimum temperature are significant. This could affect the accuracy of the forecasting results (a)

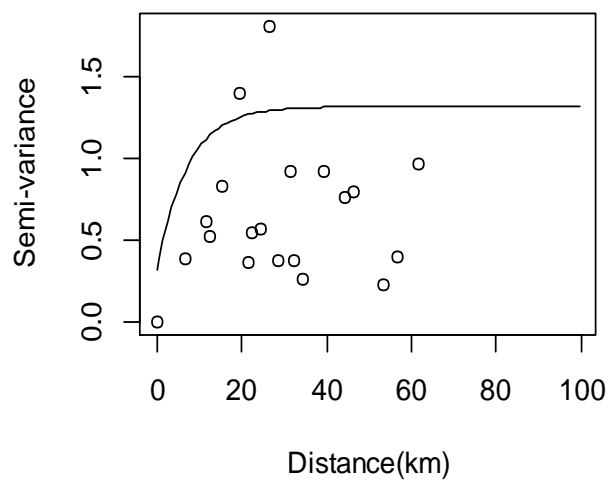

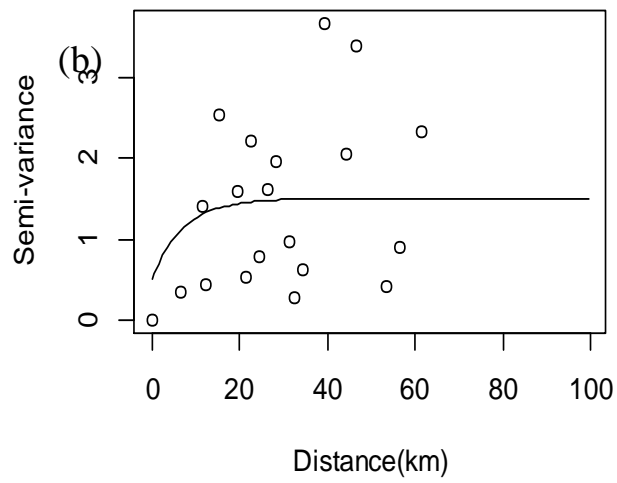

Figure 5: Empirical semivariogram of (a) maximum temperature. (b) minimum temperature over 30-day training period without Citeko station.

Figure 5 shows the adjustment of exponential semivariogram which is significant when compared with the semivariogram in Figure $3 \mathrm{a}$ which involves Citeko station. The semivariogram in Figure 5 could follow the spatial pattern from empirical semivariogram with range $7.14 \mathrm{~km}$ and sill recording of $1.317 \mathrm{~km}$ for maximum and $1.505 \mathrm{~km}$ for minimum temperature. This is an indication that spatial simulation might be more capable of modifying residual data testing, thereby producing more accurate forecasting results

The evaluation of GOP model without Citeko station gives better results, i.e. the better accuracy (lower RMSE), more reliable (lower CRPS) and better calibrated (the coverage of minimum temperature is closer to 90\%). In addition, the RMSE of NWP without Citeko station is better than that of NWP with Citeko, despite the fact that the RMSE of minimum temperature by GOP is not better than RMSE of NWP. What could be responsible for this is the inclusion of Dermaga station in this study, which is also geographically far from the other stations.

Considering Table 4, it is clear that the effects of far stations are significant on the accuracy and precision of both the GOP and NWP models for temperature forecasting. Aside that, Citeko station is located on a higher elevation compared with other stations, hence, possesses different geographic characteristics.

Table 4: Comparison of evaluating GOP and NWP, January 31 ${ }^{\text {st }}, 2009$ - December $31^{\text {st }}, 2010$.

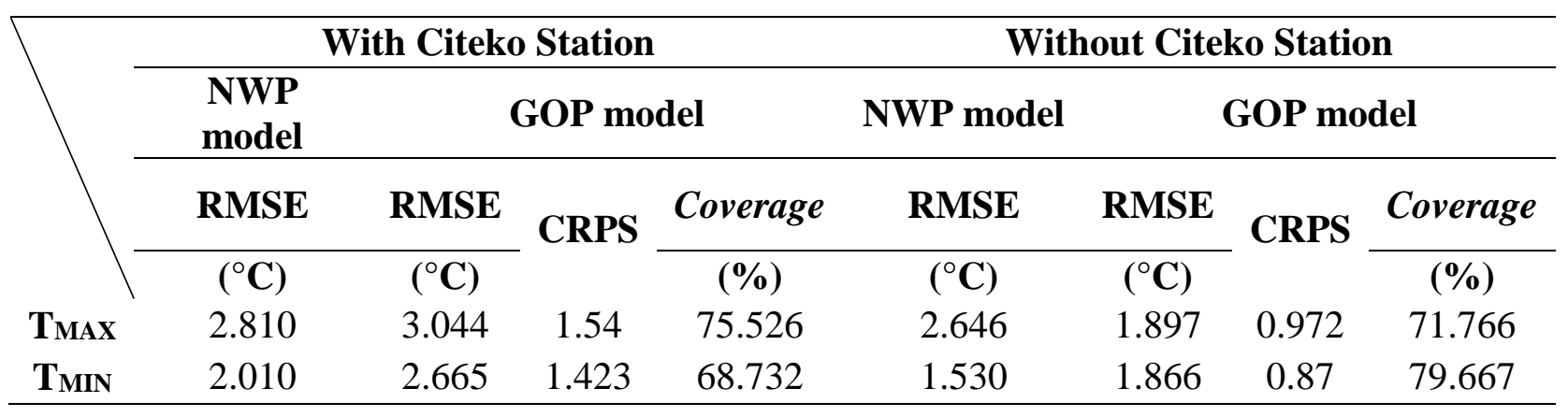


The predictive checking for GOP ensemble predictions in all stations (i.e. without Citeko station) in the period January
1, 2009 to December 31, 2010, were applied to assess its predictive performance.

(a)

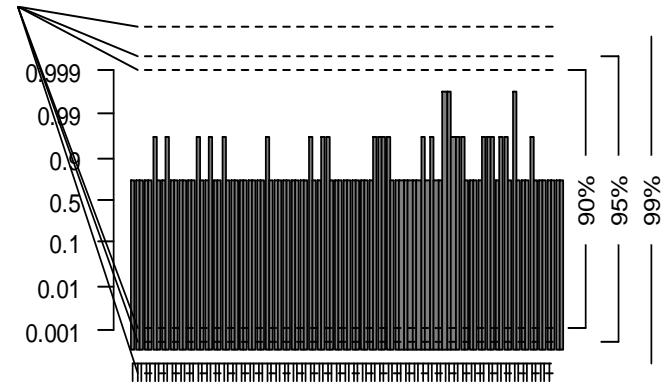

$\begin{array}{llllllllll}1 & 9 & 18 & 28 & 38 & 48 & 58 & 68 & 78 & 88\end{array}$

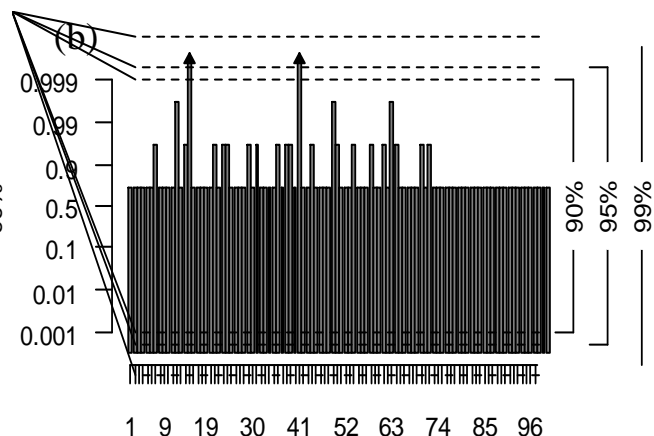

Figure 6: Verification rank histogram for GOP ensemble predictions, January $31^{\text {st }}, 2009$ December $31^{\text {st }}, 2010$ without Citeko station: (a) maximum temperature and (b) minimum temperature

The abscissa in Figure 7 shows the number of GOP ensemble and probable ordinate. The verification rank histogram for maximum and minimum temperature without Citeko station, are relatively close to the ones in Figure 5 with Citeko, thereby indicating proper coverage of the prediction intervals at all levels. Although the verification rank histogram for minimum temperature seems not better with Citeko, the GOP result in Table 4 was used in the evaluation. Therefore, this study concludes that GOP ensemble without Citeko shows better predictions than with Citeko station.

\section{CONCLUSION}

This study proposes a GOP model for analyzing the spatial relation in eight stations for the purpose of obtaining better accuracy and precision of weather forecasting and to investigate the underlying analysis in those several stations. The findings showed that exponential is the best distribution model for analyzing both the maximum and minimum temperature in Indonesia using GOP. Also, the exclusion of Citeko station in the GOP modeling for temperature in Indonesia gives better results in terms of accuracy and precision, which increase by almost twice in all stations. Considering the fact that this study involves only eight stations, the GOP might not be totally accurate in estimating the optimum parameters at these stations, as better results could be obtained with more meteorological stations, at least a dozen, in quite close locations. This has the capacity to minimize inaccurate forecasting because locations geographically far from others have higher percentage of giving inaccurate forecasts.

\section{ACKNOWLEDGMENT}

The authors wish to thank the Meteorology, Climatology and Geophysics Agency (BMKG) of Indonesia for providing all the data used in this study. A big thank also to the Ministry of Research, Technology and Higher Education of Indonesia for providing the grant for the National Strategic Research 2018, of which the authors are beneficiaries.

\section{REFERENCES}

Anggraeni, D. (2013). Calibration forecasting rainfall ensemble data using output statistic model ensemble (EMOS) and Bayesian model averaging (BMA). Surabaya: Thesis, Institut Teknologi 
Sepuluh Nopember.

Anselin, L. (1988). Spatial Econometrics: Methods and Models. Dordrecht: Kluwer Academic Publisher.

Berrocal, V., Raftery, A., and Gneiting, T. (2007). Combining spatial statistical and ensemble information in probabilistic weather forecast. Monthly Weather Review AMS, 135: 1386-1402.

BMKG. (2011). Study and model application of CCAM (conformal-cubic atmospheric model) model for short term weather forecast using MOS (model output statistics). Jakarta: Research and Development Center BMKG.

Cliff, A., and Ord, J. (1981). Spatial Processes: Models \& Applications. London: Pion Limited.

Cressie, N. (1985). Fitting variogram models by weighted least squares. Mathematical Geology, 5(17): 563585.

Cressie, N. (1993). Statistics for Spatial Data Revised Edition. New Jersey: John Wiley and Sons, Inc.

Feldmann, K. (2012). Statistical Postprocessing of Ensemble Forecasts for Temperature: The Importance of Spatial Modeling. Germany: Diplomarbeit, Ruperto-Carola University of Heidelberg.

Gel, Y., Raftery, A., and Gneiting, T. (2004). Calibrated probabilistic mesoscale weather field forecasting: The Geostatistical Output Perturbation (GOP) method (with discussion). Journal of the American Statistical Association, 99(467): 575-583.
Karl, J. W., and Maurer, B. A. (2010). Spatial dependence of predictions from image segmentation: A variogram-based method to determine appropriate scales for producing land-management information. Ecological Informatics, 5(3): 194-202.

Luthfi, M., Sutikno, and Purhadi. (2018). Calibrating weather forecast using Bayesian model averaging and geostatistical output perturbation. Journal of Science, 3(1): 1-9.

Moller, A. (2014). Multivariate and spatial ensemble postprocessing methods. Germany: Dissertation. RupertoCarola University of Heidelberg.

Narendra, R. D., Sutikno, and Purhadi. (2017). Ensemble model output statistics for short-term weather forecast. In ICoMSE 2017: The 1st Annual International Conference on Mathematics, Science, and Education. Malang, Indonesia.

Safitri, R., and Sutikno. (2012). Model output statistics with projection pursuit regression to predict minimum, maximum temperature and humidity. Jurnal Sains dan Seni ITS, 1(1): 2301928X.

Tanudidjaja. (1993). Earth and Space Science. Jakarta: Publisher Department of Education and Culture.

Tjasyono, B., and Harijono, S. (2008). Indonesian Meteorology Model 2 of Clouds and Monsoon Rain. Meteorology and Geophysics Agency Jakarta.

Wilks, D. (2006). Statistical Methods in the Atmospheric Sciences 2nd Edition. Boston: Elsevier. 